\title{
KAJIAN LIGHTING PATTERNS PADA KARYA FOTOGRAFI MODEL PAMERAN KIRANA DAKARA 2021
}

\author{
Rezki Gautama Tanrere
}

Diterima Oktober. o6, 2021; Disetujui Desember. o8, 2021

\begin{abstract}
Abstrak: Lighting patterns merupakan teknik pengaturan pencahayaan dalam fotografi potret dengan memperhatikan bentuk cahaya dan bayangan pada wajah subjek yaitu seorang model. Teknik lighting patterns ini diterapkan pada karya-karya fotografi dalam pameran Kirana Dakara 2021 yang merupakan pameran oleh mahasiswa pengampu mata kuliah Advanced Photography program studi Desain Komunikasi Visual, Universitas Multimedia Nusantara yang diselenggarakan di Dharma Negara Alaya, Denpasar, Bali. Hasil penelitian yang dilakukan menunjukkan bahwa penggunaan berbagai jenis lighting patterns memiliki peran dan fungsi yang berbeda. Dengan pemilihan lighting patterns yang tepat, hasil karya foto dapat memberikan pesan dan kesan yang sesuai dengan konsep maupun tema yang ingin dicapai oleh fotografer. Alhasil penggunaan berbagai jenis lighting patterns pada karya fotografi yang dipamerkan dalam Kirana Dakara 2021 dapat menjadi salah satu media visual yang ampuh dalam memperkenalkan karakter-karakter legenda nusantara Indonesia.
\end{abstract}

Kata Kunci: lighting patterns; fotografi model; pameran fotografi

Abstract: Lighting patterns is a technique of lighting settings in portrait photography that pays attention to the shapes of light and shadow on the subject's face, in general a model. This lighting patterns technique are applied on the photographic works at Kirana Dakara 2021 exhibition, an exhibition by students from Advanced Photography course in the Visual Communication Design study program, Multimedia Nusantara University, held at Dharma Negara Alaya, Denpasar, Bali. The results of this research conducted indicate that the use of various types of lighting patterns has different roles and functions. By choosing the right lighting patterns, each photo works can give a message and impression that is in accordance with the concept and theme that the photographer wants to achieve. As a result, the use of various types of lighting patterns in the photographic works exhibited at Kirana Dakara 2021 can be a powerful visual medium in introducing the legendary characters of the Indonesian archipelago.

Keywords: lighting patterns; model photography; photography exhibition

${ }^{1}$ Rezki Gautama Tanrere adalah staff pengajar prodi Desain Komunikasi Visual, Fakultas Seni dan Desain Universitas Multimedia Nusantara (UMN) Tangerang. e-mail : rezki.gautama@lecturer.umn.ac.id 


\section{Pendahuluan}

Cahaya (light) dalam fotografi merupakan elemen yang sangat penting dalam menghasilkan sebuah gambar melalui perangkat media rekam berupa kamera agar mendapatkan paparan intensitas cahaya (exposure) yang tepat (Wahyu Dharsito 2014: 4). Intensitas cahaya dapat dipahami melalui pemahaman dasar segitiga exposure yaitu ISO, shutter speed, dan aperture, namun dalam menghasilkan foto yang menarik tidak hanya dibutuhkan pengaturan exposure yang tepat, terdapat pengaturan hal lainnya yang sama pentingnya yaitu pengaturan pencahayaan (lighting). Pengaturan pencahayaan (lighting) yang berbeda dapat memberikan suasana dan kesan foto yang berbeda pula, oleh karena itu dalam fotografi model diperlukan pengetahuan tentang pola cahaya (lighting patterns) untuk menghasilkan foto dengan konsep maupun tema yang diinginkan. Lighting patterns merupakan teknik dalam fotografi model dengan cara mengatur intensitas cahaya, posisi cahaya, arah cahaya, jumlah pencahayaan, serta pemakaian aksesoris tambahan pembantu maupun pembentukan pencahayaan. Teknik lighting patterns ini diterapkan dalam fotografi model yang ditampilkan pada pameran fotografi Kirana Dakara 2021.

Kirana Dakara merupakan pameran dengan konten utama berupa karya-karya fotografi yang diadakan oleh mahasiswa pengampu mata kuliah Advanced Photography program studi Desain Komunikasi Visual, Universitas Multimedia Nusantara. Pada tahun 2019, Kirana Dakara mengadakan pameran pertamanya di Kota Bangkok, Thailand. Pada tahun 2021, Kirana Dakara kembali mengadakan pameran keduanya selama tiga hari mulai dari tanggal 21 hingga 23 Juli 2021 di Dharma Negara Alaya, Denpasar, Bali. Jumlah karya yang dipamerkan sebanyak 86 karya, sebagian besar karya yang dipamerkan merupakan karya fotografi.
Namun terdapat pula karya-karya seni dari media lainnya seperti lukisan pada media kanvas, lukisan pada media tekstil, ilustrasi digital, perancangan suara, dan karya seni instalasi. Meskipun memiliki jenis dan karakter yang beragam, karyakarya tersebut dapat membentuk satu kesatuan konsep yang kuat yang mengikuti tema utama pamerannya.

Konsep utama Kirana Dakara berasal dari bahasa Jawa kuno yang berarti kecantikan yang dikenang sepanjang masa, melalui konsep tersebut prioritas utama yang ditampilkan adalah kecantikan. Pada tahun 2021, Kirana Dakara mengambil tema kecantikan legenda dan kepahlawanan nusantara, dan untuk mendukung tema ini diperlukan proses kurasi karya yang tepat sehingga konsep tiap karya dapat sinkron dengan tema. Salah satu aspek penting yang dipertimbangkan oleh para kurator dalam proses kurasi merupakan lighting patterns yang hadir pada karya-karya fotografi.

\section{Metode Penelitian}

Penulis mendalami permasalahan mengenai penerapan lighting patterns pada karya fotografi model yang ditampilkan dalam pameran Kirana Dakara 2021. Masalah didalami menggunakan metode kualitatif. Data primer didapatkan melalui observasi terhadap sampel hasil beberapa foto yang dipamerkan dalam pameran fotografi Kirana Dakara 2021 dengan pendekatan teori berbagai penerapan jenis lighting patterns. Sementara itu, data sekunder didapatkan melalui teori terkait pencahayaan baik secara component light source maupun light source positioning dalam fotografi.

Analisis data hasil observasi yang difokuskan pada karya foto model dikaji menggunakan teori semiotika Ferdinand De Saussure dengan mengidentifikasi tanda yang hadir melalui makna signifi- 
er (penanda) dan signified (petanda) dari pembentukan lighting patterns yang pada karya-karya foto. Kerangka pikir yang digunakan penulis dalam penelitian ini dapat dilihat melalui bagan pada Gambar 1. Hasil analisis tersebut kemudian disimpulkan menjadi jawaban dari masalah yang dibahas dalam penelitian.

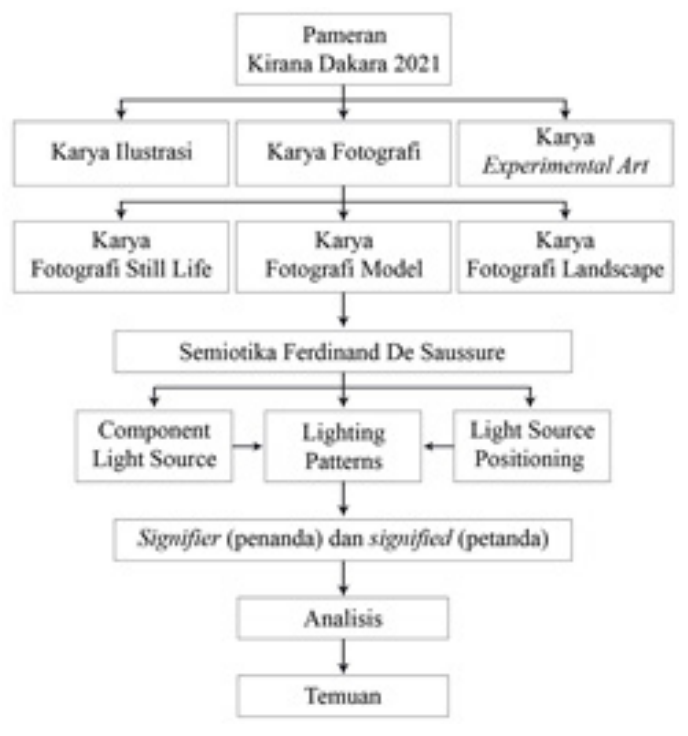

Gambar 1. Bagan Kerangka Pikir

\section{Hasil dan Pembahasan}

\section{Karakteristik Cahaya}

Fotografi secara literatur dapat diartikan sebagai melukis dengan cahaya. Cahaya dapat diibaratkan sebagai media lukis dengan beraneka ukuran bentuk dan ketajaman. Pemilihan dan penggunaan alat yang tepat beserta teknik yang sesuai akan menampilkan detail, dimensi, serta memunculkan karakter sesuai konsep fotografer (Wahyu Dharsito 2014: 4). Pengaturan pencahayaan mengacu pada empat karakteristik utama yaitu intensitas, kualitas, warna, dan arah cahaya.

Intensitas merupakan karakter utama yang dikenal dengan kata sifat terang dan redup. Intensitas mempengaruhi exposure dari gambar yang dihasilkan melalui pengaturan tiga faktor teknik utama dalam fotografi yaitu ISO, aperture, dan shutter speed. Faktor lain yang berhubungan dengan intensitas cahaya yaitu durasi, yang dibagi menjadi dua jenis yaitu pencahayaan kontinu (cahaya terus menerus) dan pencahayaan kilat (cahaya yang menyala sekilatan bersama dengan pemotretan).

Kualitas pencahayaan dapat dibagi menjadi hard light dan soft light. Hard light memiliki karakter keras, kontras, dan bayangan yang tajam. Sedangkan soft light memiliki karakter lembut, gradasi yang halus, dan bayangan yang lembut. Pembentukan cahaya menjadi hard light atau soft light tergantung pada luas sumber cahaya dan jarak terhadap objek (Wahyu Dharsito 2014: 6).

Setiap sumber cahaya memiliki komposisi spektrum warna yang berbeda-beda. Perbedaan spektrum warna ini menyebabkan ciri khas pada masing-masing sumber cahaya. Dan karakteristik yang terakhir yaitu penerapan cahaya dapat dilakukan dari berbagai arah dari atas, depan, samping, bawah, atau belakang. Penempatan arah cahaya yang berbeda akan memberikan efek terang gelap atau pembentukan yang berbeda-beda pada objek. Pembentukan bagian yang terang, gelap, atau bayangan mampu memberikan kesan visual yang berbeda.

Kesan atau citra yang disampaikan dalam sebuah foto tidak hanya dibentuk oleh cahaya, namun juga oleh bayangan. Cahaya membentuk sisi terang dan menimbulkan bayangan pada bagian yang tidak menerima cahaya, sehingga adanya bagian gelap memberikan kesan, bentuk, tekstur, dimensi, dan kontur dari objek. Kehadiran cahaya dan bayangan pada objek tidak sekedar ditampilkan, namun harus memiliki bentuk secara spesifik sehingga menimbulkan kesan yang lebih mendalam pada makna foto, hal ini dapat diterapkan melalui pembentukan lighting 
patterns.

\section{Lighting Patterns}

Intensitas, kualitas, dan arah cahaya dalam fotografi diterapkan melalui component light source yaitu pemilihan, jumlah, fungsi, dan posisi lampu. Terdapat enam jenis component light source yaitu main light sebagai lampu utama, fill light sebagai lampu pembantu, serta rim light, hair light, back light, dan background light sebagai penambah aksen cahaya yang memberikan kesan hidup pada foto. Selain pengaturan component light source, pengaturan selanjutnya adalah light source positioning yaitu pemilihan posisi objek terhadap cahaya utama sehingga menimbulkan bagian yang terang dan gelap. Hal ini ditandai dengan jatuhnya cahaya dan bayangan pada sisi objek yang terlihat dalam hasil foto. Terdapat dua jenis light source positioning yaitu broad lighting dan short lighting. Pada broad lighting, main light menerangi sisi wajah model yang menghadap ke arah kamera, sedangkan sisi wajah yang lebih jauh dari kamera mendapat cahaya dengan intensitas yang lebih kecil (Prakel, 2010: 43). Broad lighting dapat membuat wajah terlihat lebih berisi dan umumnya diterapkan pada model berwajah tirus supaya terlihat lebih lebar. Sedangkan pada short lighting, main light menerangi sisi wajah model yang berlawanan arah dari kamera sehingga sisi wajah yang lebih dekat dari kamera mendapat intensitas cahaya yang lebih sedikit (Prakel, 2010: 43). Short lighting memperkuat kontur wajah dengan aplikasi kuat atau lemahnya intensitas cahaya. Short lighting dapat membuat wajah terlihat lebih tirus, sehingga umumnya diterapkan pada model berwajah bulat agar terlihat lebih ramping.

Selain itu terdapat pula hal esensial dalam pengaturan lighting fotografi yaitu pengaturan lighting patterns yang merupakan teknik pengaturan posisi serta sudut jatuhnya cahaya dan bayangan sehingga dapat membentuk pola cahaya atau pola bayangan dengan bentuk yang spesifik. Lighting patterns menggambarkan hubungan antara sumber cahaya dengan objek utama dalam foto yaitu wajah model dan tidak ada hubungannya dengan posisi wajah terhadap kamera. Lighting patterns bersifat mengikuti arah wajah model dan apabila terjadi perubahan posisi wajah dari tampilan depan, sumber cahaya harus ikut berubah mengikuti posisi wajah untuk menjaga lighting patterns. Terdapat empat jenis lighting patterns, yaitu butterfly lighting atau yang sering disebut sebagai paramount lighting, rembrandt lighting, loop lighting, dan side lighting.

\section{Butterfly Lighting}

Butterfly lighting atau juga dikenal sebagai paramount lighting merupakan lighting patterns yang ditandai dengan kehadiran bayangan berbentuk segitiga atau menyerupai siluet kupu-kupu langsung di bawah hidung. Butterfly lighting dihasilkan dengan menempatkan main light di atas wajah model, segaris lurus dengan hidung model, hal ini dapat dilihat melalui diagram pemotretan yang ada di gambar 2. Posisi yang cukup tinggi diperlukan untuk menciptakan bayangan di bawah hidung dan dagu pada model.

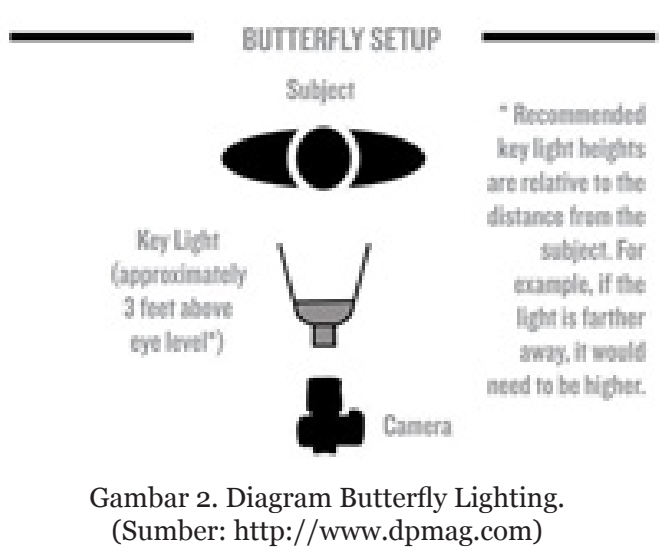


Butterfly lighting dianggap sebagai pencahayaan bergaya glamour dengan terciptanya garis bayangan pada pipi model sehingga yang menonjolkan tulang pipi dan garis rahang, serta garis bayangan tipis pada tulang hidung sehingga hidung model terlihat lebih mancung atau runcing. Pola pencahayaan ini cocok untuk model berwajah tirus, namun kurang ideal untuk wajah yang berisi. Butterfly lighting juga dikenal sebagai salah satu pencahayaan yang digunakan sebagai foto kecantikan maupun produk-produk kecantikan (Dantzig, 2010: 32).

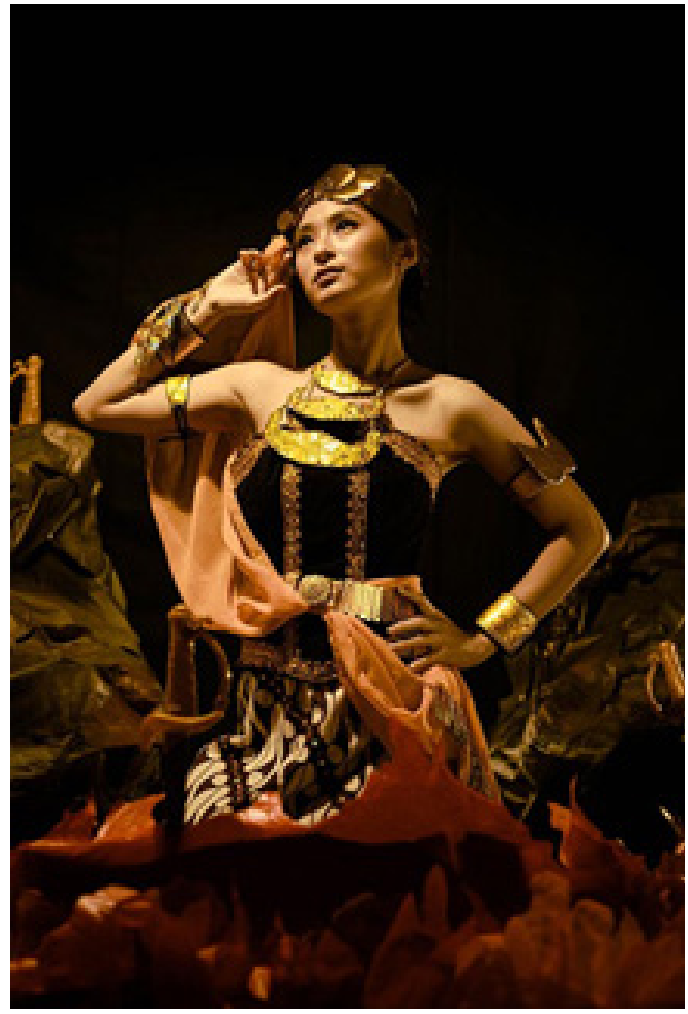

Gambar 3. Karya Foto Sinta si Suci, Cantik nan Setia (Sumber: Kirana Dakara 2021)

Salah satu karya foto pada pameran Kirana Dakara 2021 yang menggunakan teknik lighting patterns dengan butterfly lighting yaitu karya berjudul Sinta si Suci, Cantik nan Setia yang dapat dilihat pada gambar 3. Hal ini dapat diidentifika-

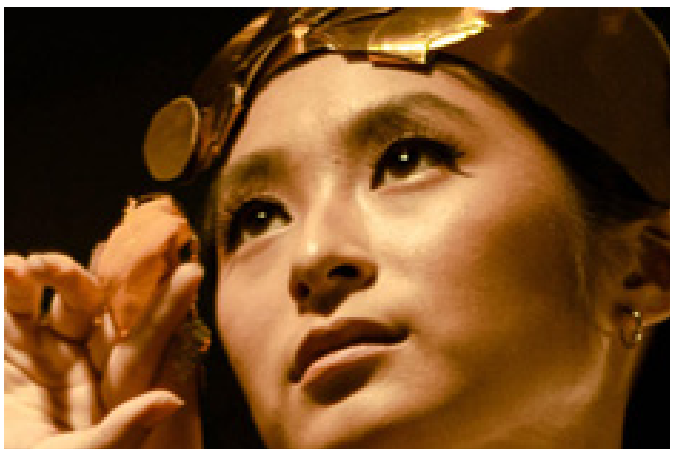

Gambar 4. Close Up Karya Foto Sinta si Suci, Cantik nan Setia

(Sumber: Kirana Dakara 2021)

si melalui penanda kehadiran bayangan berbentuk segitiga yang terdapat tepat pada bagian bawah hidung model yang dapat dilihat secara close up pada gambar 4, sehingga petanda yang dapat diketahui melalui foto ini, yaitu penempatan posisi sumber cahaya utama berada tepat di depan wajah model dengan ketinggian yang cukup signifikan antara $90 \mathrm{~cm}$ hingga 120 $\mathrm{cm}$ di atas wajah model. Petanda dengan penempatan posisi sumber cahaya tersebut mempertegas garis rahang dan tulang pipi sehingga mempertegas struktur wajah model agar terlihat lebih tirus dan anggun, hal ini dinamakan adanya penggunaan lighting patterns dengan teknik butterfly lighting.

Karya ini menampilkan Sinta sebagai salah satu tokoh protagonis pada kisah Ramayana yang menceritakan kesetiaan dan kesucian cinta kepada Rama. Latar depan berupa kobaran api merupakan penggambaran kondisi kobaran api saat Kerajaan Alengka jatuh dan kesetiaan cinta Shinta yang rela menceburkan diri ke dalam kobaran api.

Penggunaan butterfly lighting dapat memperkuat karakter tokoh Sinta menjadi lebih glamour. Hal ini dapat terlihat dengan munculnya garis bayangan pada tulang pipi wajah model sehingga memperkuat struktur wajah model agar terli- 
hat lebih tirus, selain itu kehadiran garis bayangan pada tulang hidung menghasilkan kesan hidung yang lebih mancung pada model. Sifat-sifat pembentukan cahaya dan bayangan tersebut diidentifikasi sebagai bentuk fisik layaknya kata cantik pada seseorang, hal ini sesuai dengan karakter Sinta yang dikenal akan kecantikannya.

\section{Rembrandt Lighting}

Rembrandt lighting merupakan lighting patterns yang ditandai dengan bentuk segitiga cahaya pada pipi atau di bawah mata model. Cahaya yang terpapar pada salah satu sisi muka model menembus melalui lekukan hidung untuk menerangi tulang pipi pada sisi yang tidak terkena cahaya sehingga menghasilkan pembentukan cahaya segitiga (Prakel, 2010: 205). Rembrandt lighting dinamai dari pelukis Belanda abad ke-17, bernama Rembrandt van Rijnabad yang dikenal dengan teknik Chiaroscuro dengan menekankan cahaya dan bayangan pada wajah model, sehingga menambahkan kesan misteri dan dramatis.

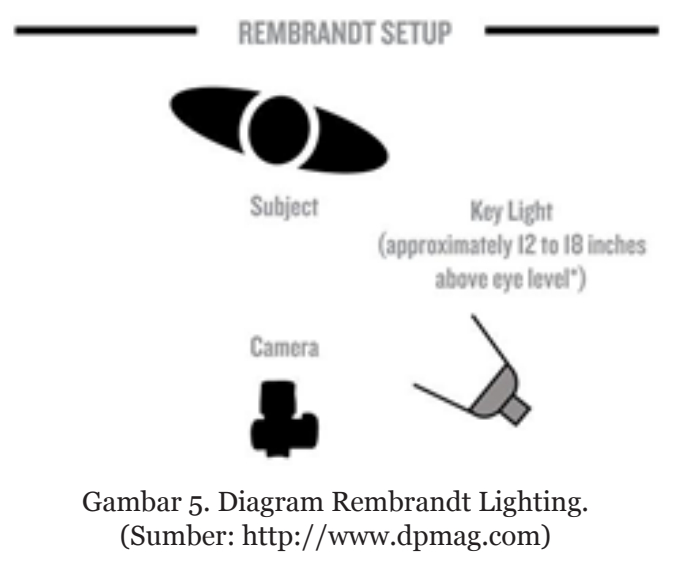

Pembentukan rembrandt lighting menyerupai loop lighting, namun sumber cahaya lebih turun ke arah kiri atau kanan wajah model, hal ini dapat dilihat melalui diagram pemotretan yang ada di gambar
5. Rembrandt lighting dianggap sebagai pencahayaan bergaya natural yang dapat pula meningkatkan bentuk dan tekstur wajah model.

Karya foto berjudul Bara, Lara, dan Nestapa yang dapat dilihat di Gambar 6, merupakan salah satu karya dalam Kirana Dakara 2021 yang menggunakan teknik lighting patterns secara rembrandt lighting. Hal ini dapat diketahui dengan penanda kehadiran cahaya berbentuk segitiga pada pipi kanan di bawah mata model yang dapat dilihat secara close up pada Gambar 7. Penanda ini dapat diidentifikasi sebagai petanda bahwa posisi sumber cahaya berada pada serong kiri model dengan ketinggian sekitar 30 hingga $45 \mathrm{~cm}$ di atas wajah model. Petanda melalui pengaturan posisi sumber cahaya utama tersebut memperkuat tekstur wajah model sehingga terlihat lebih natural namun dalam kesan lebih dramatis seakan model diterangi dengan pencahayaan secara alami, hal ini dapat ditandai bahwa karya menggunakan lighting patterns dengan teknik rembrandt lighting.

Hasil karya Bara, Lara, dan Nestapa menggambarkan sosok Srikandi yaitu dewi perang wanita dalam mitologi Jawa. Kata bara menggambarkan sosok Srikandi yang berjiwa api pada peperangan yang kelam dengan suasana lara dan nestapa. Penggunaan rembrandt lighting pada foto ini menghasilkan efek dramatisasi, hal ini dapat terlihat dari kekontrasan antara terang dan gelap cahaya pada wajah model. Penegasan bentuk segitiga di bawah mata model menghasilkan ciri khas pencahayaan yang natural, serta penegasan tekstur wajah yang memberi penekanan karakter sesuai dengan tema dan konsep yang diinginkan. 


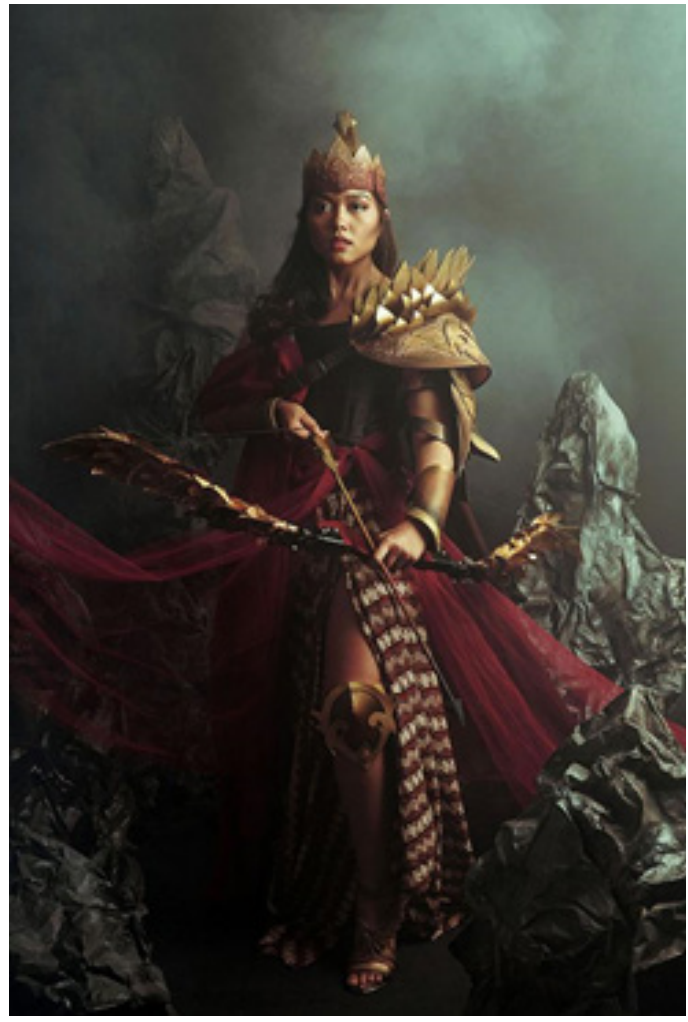

Gambar 6. Karya Foto Bara, Lara, dan Nestapa (Sumber: Kirana Dakara 2021)

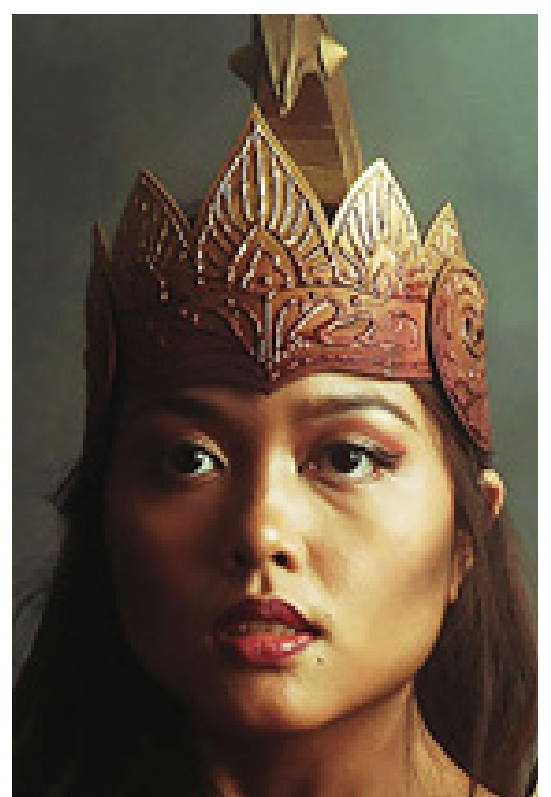

Gambar 6. Karya Foto Bara, Lara, dan Nestapa (Sumber: Kirana Dakara 2021)

\section{Loop Lighting}

Loop lighting merupakan lighting patterns yang ditandai dengan adanya bayangan berbentuk lingkaran pada bagian samping bawah hidung. Loop lighting dihasilkan dengan menempatkan main light di atas sumbu kamera namun pada posisi sedikit ke kanan atau kiri dari arah model dimana diagram pemotretan dapat dilihat melalui gambar 8. Cahaya yang tercipta dari segitiga rembrandt lighting pada loop lighting memanjang dan menyebar sehingga bayangan lingkaran yang tercipta dapat terlihat dengan jelas dan tidak menyebar hingga hilang ke dalam bayangan luar pipi atau bawah mulut (Dantzig, 2010: 30).

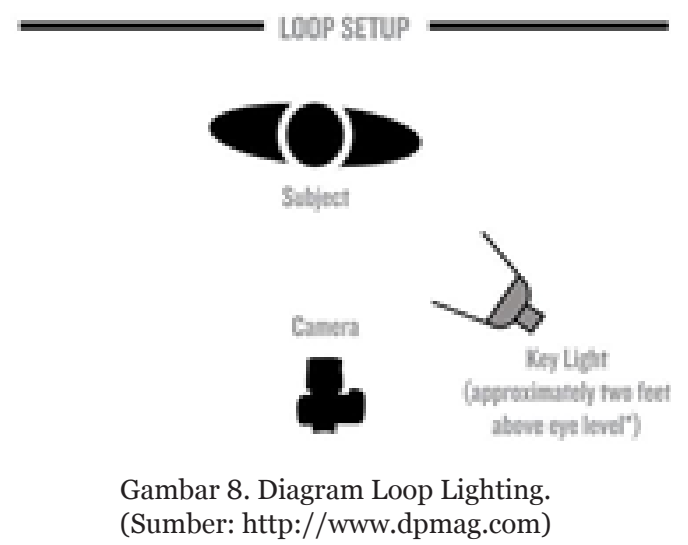

Loop lighting dianggap sebagai pencahayaan dasar bagi banyak foto potret karena tidak menampilkan dramatisasi namun tetap tidak datar maupun polos, sehingga pola tersebut cocok untuk berbagai wajah, namun lebih cocok untuk wajah berbentuk oval.

Salah satu karya fotografi model yang dipamerkan pada Kirana Dakara 2021 dengan menggunakan teknik loop lighting yaitu karya berjudul Legenda Putri Tingang yang dapat dilihat pada gambar 9. Secara close up yang dapat dilihat secara gambar 10, dapat diketahui dengan kehadiran penanda bayangan berbentuk lingkaran di samping kiri bawah hidung 
model. Penanda ini menjadi petanda bahwa posisi sumber cahaya berada pada serong kiri wajah model dengan ketinggian antara $60 \mathrm{~cm}$ hingga $90 \mathrm{~cm}$ dari tinggi wajah model, dengan penempatan posisi sumber cahaya tersebut terlihat pencahayaan pada wajah model tidak datar dan terlihat natural namun tidak terkesan dramatis. Selain itu dengan kehadiran pola bayangan berbentuk oval di samping hidung menghasilkan bentuk wajah oval model agar terlihat lebih tirus, hal ini dinamakan adanya penggunaan lighting patterns yang ditandai dengan penggunaan teknik loop lighting di dalam sebuah karya fotografi model.

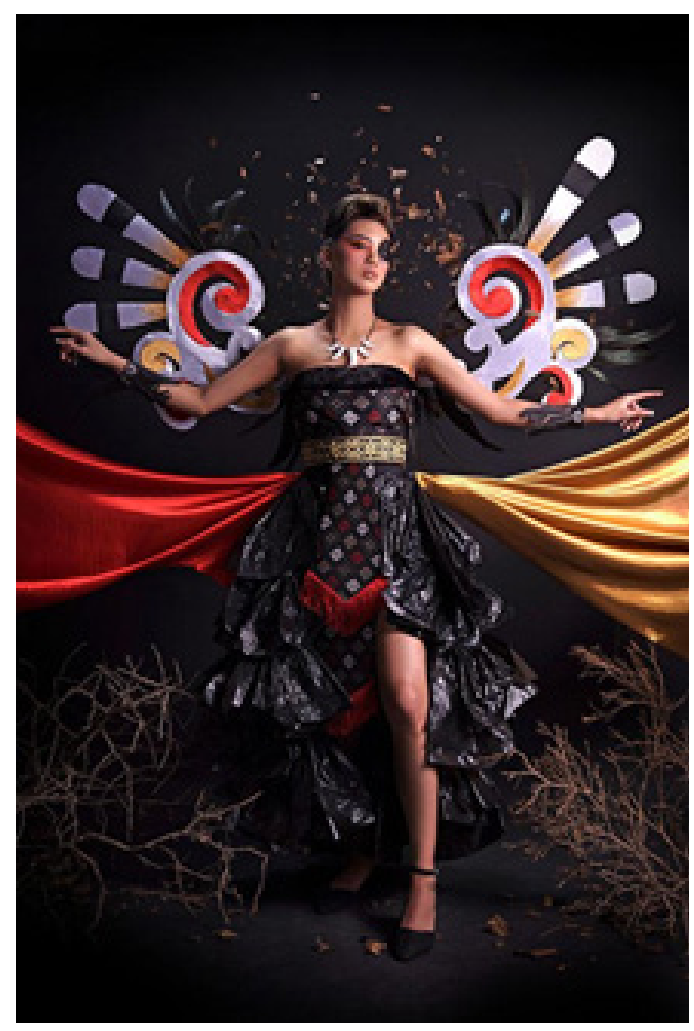

Gambar 9. Karya Foto Legenda Putri Tingang (Sumber: Kirana Dakara 2021)

Karya tersebut mengangkat cerita rakyat Dohong dan Tingang dari Kalimantan Tengah. Pada karya ini ditampilkan seorang wanita sebagai Putri Intan yang sedang bertransformasi menjadi seekor

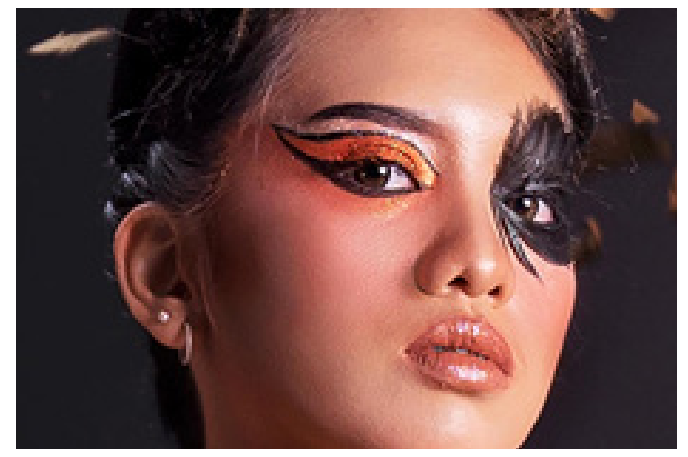

Gambar 10. Close Up Karya Foto Legenda Putri Tingang

(Sumber: Kirana Dakara 2021)

burung tingang. Latar belakang hitam dan gelap dengan daun-daun kering beserta ranting yang jatuh menggambarkan suasana gelapnya hutan tempat Putri Intan dikutuk menjadi burung tingang serta menggambarkan pula kesan kemalangannya. Di tengah kemalangannya tersebut, Putri Intan masih menunjukkan pesona dan kecantikan yang luar biasa sebagai burung tingang. Penggunaan loop lighting digunakan untuk mempertahankan bentuk muka model yang oval sehingga tetap terlihat tirus. Selain itu, penggunaan loop lighting menghasilkan cahaya dan bayangan yang tidak datar dan lebih alami namun tidak menutupi efek transformasi kecantikan pada riasan, wardrobe dan keseluruhan konsep model.

\section{Side Lighting}

Jenis lighting patterns yang terakhir yaitu side lighting dihasilkan dengan menempatkan main light pada posisi kanan atau kiri dari arah samping wajah model dan setara dengan tingkat mata, hal ini diilustrasikan melalui diagram pemotretan yang ada di Gambar 11.

Pencahayaan dari samping wajah model menghasilkan bayangan pada setengah sisi lainnya, hal ini dapat memberikan kesan yang sangat dramatis dan 


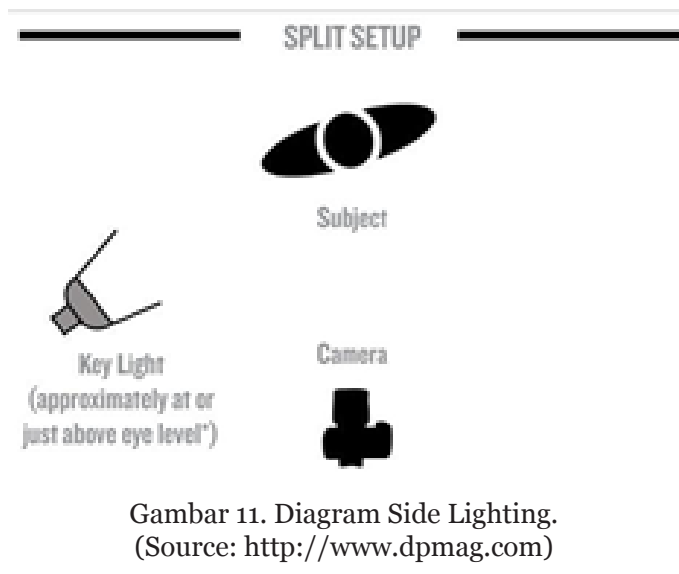

maskulin karena wajah yang terbelah sempurna di tengah garis hidung dengan menciptakan sisi terang dan gelap pada wajah model (Prakel, 2010: 225). Selain itu, side lighting dapat pula mempertegas tekstur pada permukaan wajah model pada sisi yang terpapar cahaya.

Karya foto dalam Kirana Dakara 2021 yang menggunakan teknik side lighting yaitu karya berjudul Nyi Blorong, yang dapat dilihat pada Gambar 12. Hal ini diidentifikasi melalui penanda bentuk bayangan yang terdapat pada setengah sisi wajah model dan cahaya yang terpapar pada setengah sisi wajah lainnya yang dapat dilihat melalui Gambar 13 secara close up, sehingga petanda yang dapat diketahui dalam foto ini yaitu penempatan posisi sumber cahaya yang berada tepat di samping kiri wajah model atau kanan dari arah fotografer. Petanda melalui penempatan posisi sumber cahaya tersebut mempertegas antara gelap bayangan dan terangnya pencahayaan pada wajah model sehingga kesan dramatisasi sangat terlihat pada konsep foto dan memperkuat karakter wajah model, hal ini ditandai dengan penggunaan lighting patterns dengan teknik side lighting.

Pada karya ini digambarkan sosok Nyi Blorong yang kuat, tangguh, sakti, dan penuh kemewahan sebagai panglima

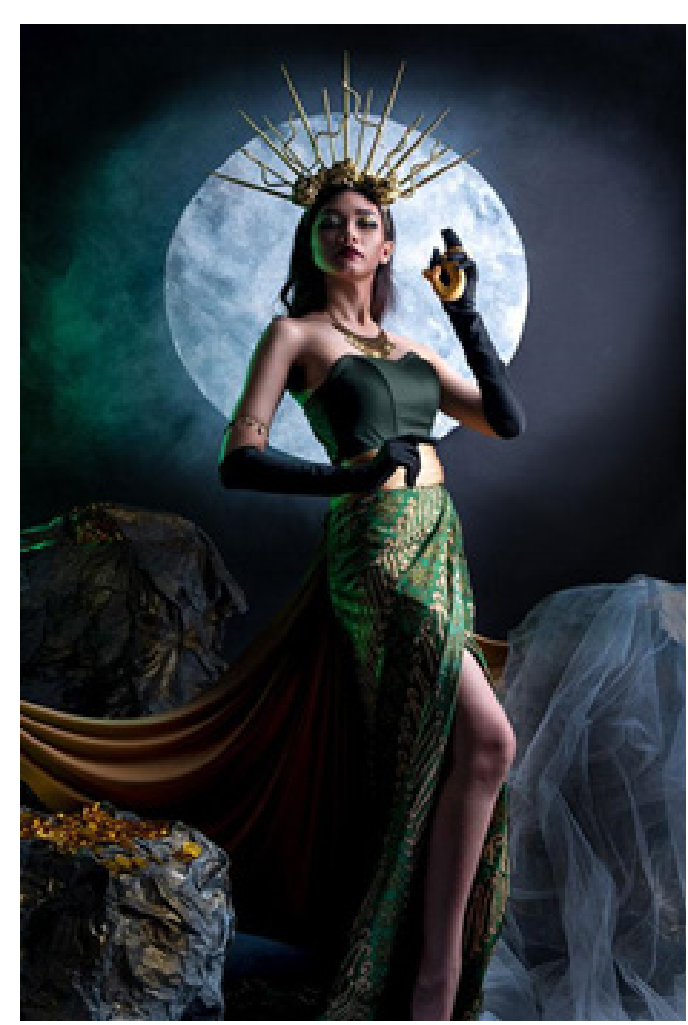

Gambar 12. Karya Nyi Blorong

(Sumber: Kirana Dakara 2021)

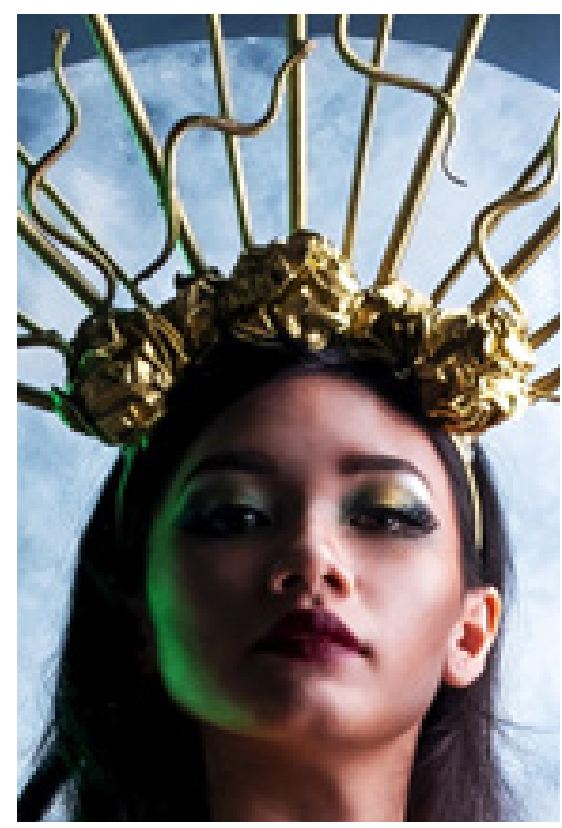

Gambar 13. Close Up Karya Nyi Blorong (Sumber: Kirana Dakara 2021) 
terkuat milik Kanjeng Ratu Kidul. Nyi Blorong memiliki wujud setengah manusia setengah ular dan merupakan penguasa keraton pantai Selatan dengan tugas untuk menyesatkan manusia agar terjerumus ke pesugihan dan menjadikan manusia sebagai budak-budaknya yang taat.

Penggunaan side lighting memperkuat karakter tokoh Nyi Blorong menjadi lebih tegas, dan kuat karena wajah model yang terpapar cahaya menjadi lebih jelas dengan terlihatnya tekstur pada wajahnya. Selain itu, kehadiran komposisi secara tonal kontras yang menampilkan kekontrasan antara terang dan gelap memberikan efek yang sangat dramatis pada hasil foto.

Kehadiran berbagai macam lighting patterns tidak hanya memperkuat bentuk fisik dari model, namun ikut mempertajam penekanan konsep dan tema yang diinginkan oleh fotografer.

\section{Kesimpulan}

Dalam fotografi potret dengan subjek utama model intensitas, jumlah, arah cahaya, serta pemakaian berbagai macam aksesoris tambahan saja tidak cukup untuk menghasilkan karakter model maupun penguatan cerita yang diinginkan. Sehingga dibutuhkan pula penerapan teknik lighting patterns yang benar dan tepat agar dapat tercipta konsep sesuai dengan tema yang diinginkan, serta mempertegas pembentukan struktur dan tekstur wajah model.

Efektivitas penggunaan lighting patterns dapat terlihat pada hasil karya foto yang dipamerkan dalam pameran Kirana Dakara 2021. Penggunaan berbagai jenis lighting patterns, yaitu butterfly lighting yang mempertegas struktur wajah model, rembrandt lighting memberikan kesan dramatis namun natural dengan pembentukan cahaya dan bayangan yang berkarakter, loop lighting dengan pencahayaan sederhana namun tetap tidak terkesan datar yang mempertahankan bentuk wajah model serta menampilkan pencahayaan yang alami, dan side lighting yang menimbulkan efek dramatis dan mempertegas tekstur wajah model yang terpapar oleh cahaya. Penggunaan lighting patterns pada Kirana Dakara 2021 ini dapat menjadi salah satu cara ampuh untuk memperkenalkan karakter maupun karakteristik legenda dan kepahlawanan Indonesia agar dapat lebih dikenal secara nasional maupun internasional.

\section{Referensi}

Bradbury, R. (2021). Mastering Lighting \& flash Photography. Sussex: Ammonite Press. Dantzig,

Dharsito, W. (2014). Basic Lighting for Photography. Jakarta: PT Elex Media Komputindo.

Fanani, F. (2013). Semiotika Strukturalisme Saussure. The Messenger, 5 (1), 10-15. http://dx.doi.org/10.26623/ themessenger.v5i1.149

Fancher, N. (2018). Chroma: A Photographer's Guide to Lighting with Color. California: Rocky Nook.

Hough, C. (2013). Studio Photography and Lighting: Art and Techniques. Marlborough: Crowood Press.

Hunter, F., Biver, S., Fuqua, P., \& Reid, R. (2021). Light, Science and magic: An Introduction to Photographic lighting. New York: Routledge.

Knight, C. (2017). The Dramatic Portrait: The Art of Crafting Light and Shadow. California: Rocky Nook.

L, J. (2012). Photographing Shadow and Light: Inside the Dramatic Lighting Techniques ans Creative Vision of Portrait Photographer. New York: Amphoto Books.

Mchugh, S,T. (2018). Understanding Pho- 
tography. San Francisco: No Starch Press.

Model, A. (2010). Basic lighting for beauty. Jakarta: PT Elex Media Komputindo.

Pegram, B. (2014). Light a Model. New York: Amherst Media.

Peterson, B. (2020). Understanding Portrait Photography. California: Watson Guptill.

Plater, S., \& Wilkinson, P. (2016). Mastering Portrait Photography. Sussex: Ammonite Press.

Prakel, D. (2010). The visual dictionary of photography. Switzerland: AVA Book.

Savini, D. (2012). Masterclass: Professional Studio Photography. California: Rocky Nook.

Sudjiman, P., Zoest, A.V. (1996). Serba-serbi Semiotika. Jakarta: PT Gramedia Pustaka Utama

Sugiyono. (2011). Semiotika Komunikasi Visual. Yogyakarta: Jalasutra.

Stephen. (2010). Portrait lighting for digital photographers. New York: Amherst Media.

Valenzuela, R. (2016). Picture perfect Lighting: An Innovative Lighting System for Photographing People. California: Rocky Nook. 